RESEARCHARTICLE

\section{The Relative Importance of Parental Numerical Opportunities, Prerequisite Knowledge and Parent Involvement as Predictors for Early Math Achievement in Young Children}

\author{
Annelies Ceulemans', Elke Baten', Tom Loeys ${ }^{2}$, Karel Hoppenbrouwers ${ }^{3}$, Daisy \\ Titeca ${ }^{1}$, Sofie Rousseau ${ }^{4}$, Annemie Desoete ${ }^{1,5 *}$ \\ ${ }^{1}$ Department of Experimental Clinical and Health Psychology, Ghent University, Belgium \\ ${ }^{2}$ Department of Data Analysis, Ghent University, Belgium \\ ${ }^{3}$ Environment and Health Unit, University of Leuven, Belgium \\ ${ }^{4}$ Parenting and Special Education Research Unit, University of Leuven, Belgium \\ ${ }^{5}$ Department of Speech-Language Therapy, Artevelde University College, Belgium
}

Open Access

Citation: Ceulemans, A., Baten, E., Loeys, T., Hoppenbrouwers, K., Titeca, D., Rousseau, S., \& Desoete, A. (2017). The Relative Importance of Parental Numerical Opportunities, Prerequisite Knowledge and Parent Involvement as Predictors for Early Math Achievement in Young Children. Interdisciplinary Education and Psychology, 1(1):6.

Received: June 28, 2017

Accepted: August 24, 2017

Published: August 30, 2017

Copyright: ๑ 2017 Desoete et al. This is an open access article distributed under the terms of the Creative Commons Attribution License, which permits unrestricted use, distribution, and reproduction in any medium, provided the original author and source are credited.

Corresponding author: Annemie Desoete, Department of Experimental Clinical and Health Psychology, Ghent University, Belgium. E-mail: annemie.desoete@UGent.be

\begin{abstract}
This study explored the relative importance of the parent-child interaction focusing on numerical cues as opportunity factor, the prerequisite knowledge as propensity factor and the general parent involvement as distal factor in the prediction of early math achievement in 31 children followed up from toddlerhood (24 months of age) till kindergarten (48 months of age). The opportunity-propensity model combines these three categories of factors to predict later achievement. The study confirmed the positive linear relationship between early math achievement and the environmental numeracy opportunities provided by parents in kindergarten above the parental general involvement. In addition, the results showed a predictive contribution of the opportunity-predictors in toddlers to late math achievement in kindergarten. There was a quadratic opportunity prediction in toddlerhood and a linear opportunity prediction in kindergarten. The implications of these findings are discussed in terms of the opportunity-propensity model in the prediction of number sense in toddlers and in kindergarten.
\end{abstract}

\section{Keywords}

counting, calculation, home environment, parental involvement, opportunity-propensity model, numerical parent-child interaction; toddlers, kindergartners

\section{Introduction}

The Opportunity-Propensity (O-P) model suggests that children are more likely to realize their potential for learning if they are provided Opportunities $(\mathrm{O})$ to learn that at school and in other contexts and have the capability or propensity $(P)$ to benefit from the opportunities provided to them (Wang et al. 2013). Opportunity indicators are culturally defined contexts in which children are presented with content to learn or given opportunities to practice math skills. Opportunity factors include factors such as home environment and parents focusing on numeracy. Propensity indicators are factors that relate to the 'ability' or 'willingness' to learn math content at school or at home. Propensity factors also deal with factors such as prerequisite knowledge and intelligence. In addition the O-P model includes antecedent factors, explaining why some children are more likely than others to benefit from the opportunities provided to them and develop stronger propensities for learning. Several antecedent variables were found to be relative important predictors of math achievement even after controlling for the $\mathrm{O}$ and $\mathrm{P}$-variables in the model. Researchers found that effect of SES as antecedent variable was often indirect and mediated through other variables. Children who came from higher SES homes, had parents who held higher educational expectations for 
them.

Analyses on secondary data using the O-P model revealed that $58-81 \%$ of the variance in math achievement could be explained by family variables and specific $\mathrm{O}$ - and P-factors. Ofactors were found to explain between $11.2-44.1 \%$ of the variance of 10th and 12th grade math. P-factors added $21.9-27.6 \%$ to the prediction of math achievement to that contributed by antecedent and opportunity factors according to the opportunity-propensity model. Antecedent factors were found to account for $28.8-43.0 \%$ of the variance in math achievement according to the O-P model. SES accounted for $2 \%$ of the variance in third grade math (Desoete \& Baten, 2017).

Thus, multiple predictors are taken into account in this O-P model. This holistic approach on learning is relatively new. Previous research on math development especially focused on isolated predictors. However, in terms of the Opportunity-Propensity- model (Byrnes \& Miller, 2007; Wang \& Byrnes, 2013), it is important to not only relate mathematical achievement to Propensity factors (P-factors), but also to investigate the role of $\mathrm{O}$-factors.

Home numeracy environment can be considered as O-factor, positively impacting the development of number sense. Parental opportunities were found to substantially affect the development of language and literacy (e.g., Dieterich, Assel, Swank, Smith, \& Landry, 2006; Hood, Conlon, \& Andrews, 2008). However, there might also be also general factors, such as the overall responsiveness of parents to their child predicting later language and literacy development (Bornstein \& TamisLeMonda, 1989; Dodici, Draper, \& Peterson, 2003).

Up till now studies on the role of home literacy opportunities have focused upon a few months old infants (e.g., Karrass \& Braungart-Rieker, 2005; Pancsofar, Vernon-Feagans, \& Family Life Project, 2010), toddlers of only a few years old, and children from kindergarten (e.g., Benavides-Varela, Butterworth, Burgio, Arcara, Lucangeli, \& Semenza, 2016; Dieterich et al., 2006; Hood et al., 2008; Roberts, Jurgens, \& Burchinal, 2005). In addition, there are, although rapidly growing (e.g. Segers, Kleemans, \& Verhoeven, 2015), still fewer studies on numeracy than on literacy.

Overall, the pattern of study results in this field indicate that kindergartners who develop in a rich numerical home numeracy environment have better number sense compared to those with a less rich home numeracy environment (e.g., Clements \& Sarama, 2014; Kleemans et al., 2012; Skwarchuk, Sowinski, \& LeFevre, 2014; Niklas, Cohrssen, \& Tayler, 2016). Nevertheless, research on the relative importance of opportunity and propensity predictors in 2-year-olds not yet entering kindergarten is scarce. However, Levine, Suriyakham, Rowe, Huttenlocher, and Gunderson (2011) demonstrated that in 14-to 30-month-olds the frequency of parental talk about numbers as 'opportunities' predicted the children's cardinal knowledge (e.g., knowing that the word 'four' refers to sets with 4 items) at 46 months of age. Consequently, not only the influence of home numeracy environment in kindergarten (e.g., Blevins-Knabe \& Musun-Miller, 1996), but also the predictive value of numerical parent-child interactions at younger age might be interesting to study. This knowledge within the O-P framework might contribute to the understanding of budding numeracy in 2-and 4-year-olds.

\section{Current study}

The given review shows that it is commonly acknowledged that language experiences are important from infancy on (e.g., Karrass \& Braungart-Rieker, 2005). Studies on numeracy, however, mainly focus on kindergartners and older children. Therefore, little is known about the relative importance of predictors of number sense in children who did not yet enter kindergarten.

The aim of the current study was to investigate the role of numeracy environment for the number sense in toddlerhood (24 months) and in kindergarten (48 months). This resulted in the following specific research questions. First, the current study aimed at confirming previous findings on the positive relationship between home numeracy opportunities and number sense in kindergarten. Second, it was questioned whether the frequency of numerical parentchild interactions as opportunity factor in toddlerhood already could affect the number sense competencies of children later on. At last, the third question handled the concurrent value of numeracy environmental opportunities for toddlers' number sense. In line with the findings of the above mentioned kindergarten studies it was expected to find positive concurrent (e.g., Blevins-Knabe \& Musun-Miller, 1996; LeFevre et al., 2009) and prospective (e.g., Kleemans 
et al., 2012) relationships for the younger children investigated in this study.

A manual search paradigm, a procedural and conceptual counting test as well as a cardinality knowledge test were respectively used to assess the toddlers' and kindergarteners number sense. In toddlers, number sense is focused on the discrimination of numerosities.

Observational data were used to map the parent-child opportunities both in toddlerhood and kindergarten. Furthermore, it was investigated if parental involvement as general factor predicted early math achievement or if it was really parents focusing on numbers or the 'opportunities' that developed the child's number sense. This was explored by taking into account parental 'involvement' as measure of the quality of the interaction between parent and child. 'Involvement' referred to the establishment of a qualitative home learning environment (e.g., Melhuish \& Phan, 2008) through one-on-one interactions between parent and child targeting the development of academic skills as a proximal form of parent involvement (Sy, Gottfried, \& Gottfried, 2013). In line with the established role of parental involvement on literacy skills (e.g., Sy et al., 2013), there is some reason to believe that this parent related antecedent factor also relates to numeracy skills in children. This is suggested by the effect of the home environment offered by parents on (informal) mathematical knowledge or numeracy skills of children (Anders et al., 2012; Blevins-Knabe, WhitsesideMansell, \& Selig, 2007). As such, the additional value of numerical experiences through parent-child interactions for early numerical competencies was questioned on top of this specific parental control measure.

\section{Method}

\section{Participants}

Participants participated in an in-depth study on early number sense and numerical competencies. Parents of 31 children consented to participate with their child at the age of 24 (T1) and 48 months (T2). See Table 1 for the sample characteristics of the current study.

Table 1. Descriptive characteristics of the sample

\begin{tabular}{|c|c|c|c|}
\hline & \multicolumn{2}{|c|}{$M$} & $(S D)$ \\
\hline $\begin{array}{l}\text { Age (in months) } \\
24 \text { months (first assessment) } \\
48 \text { months (second assessment) }\end{array}$ & \multicolumn{2}{|c|}{$\begin{array}{l}23.55 \\
48.42 \\
\end{array}$} & $\begin{array}{l}(1.18) \\
(0.92) \\
\end{array}$ \\
\hline \multirow[t]{2}{*}{$I^{a}$} & \multicolumn{2}{|c|}{101.33} & (12.53) \\
\hline & \multicolumn{2}{|c|}{ Boys $(n)$} & Girls $(n)$ \\
\hline \multirow[t]{2}{*}{ Gender } & \multicolumn{2}{|c|}{15} & 16 \\
\hline & \multicolumn{2}{|c|}{ Mothers $(n)$} & Fathers $(n)$ \\
\hline \multirow[t]{2}{*}{$\begin{array}{l}\text { Educational level }^{\mathrm{b}} \\
\text { Primary education } \\
\text { Higher secondary education } \\
\text { Higher education }\end{array}$} & \multicolumn{2}{|c|}{$\begin{array}{c}1 \\
7 \\
23\end{array}$} & $\begin{array}{c}0 \\
15 \\
13\end{array}$ \\
\hline & $\operatorname{Low}(n)^{d}$ & Medium $(n)^{\mathrm{e}}$ & High $(n)^{f}$ \\
\hline Family income $^{c}$ & 2 & 13 & 13 \\
\hline
\end{tabular}

Note. IQ = Intelligence Quotient.

${ }^{a} I Q$ retrieved from the Wechsler Preschool and Primary Scale of Intelligence - Third edition (WPPSI-IIINL; Wechsler, 2002) for all children except for one child of whom full scale IQ could not be calculated $(n=$ 30). ${ }^{b}$ Information unknown for 3 of 31 fathers. ${ }^{c}$ Three families did not disclose information on income. ${ }^{d}$ income $<€ 1500 .{ }^{e} € 1501<$ income $<€ 3000$. ${ }^{\mathrm{f}}$ income $>€ 3000$.

All parents accompanying their child for research and filling out the additional questionnaire were mothers.

For parents who cannot be with their children full-time, many child-minding options are currently available in Flanders for children between the ages of 0-3 years, both formal (e.g. day nurseries or day care, child-minding families, ... ) and informal (e.g. grandparents or other family members, friends, neighbors, ...). In the current sample child-minding options at the age of 24 months were divided as follows: no provision $(n=2)$, informal provision $(n=6)$, 
formal provision ( $n=14$; with for $n=5$ : day care and for $n=9$ : child-minding families), and a combination of informal and formal provision $(n=8$; with for $n=5$ : combined with day care, with for $n=2$ : combined with child-minding families, and for $n=1$ : combined with day care and child-minding families). For one child this information was unknown. At the age of 48 months all children attended early schooling in kindergarten.

\section{Procedure}

Children were tested at the age of 24 and 48 months. Research at 24 months took place at the 'Child \& Family' services, which are governmental services with responsibility for the guidance and support of young children and families (http://www.kindengezin.be). At that time most children attended child care when their mothers were working. The tests at 48 months took place at the children's home. In all settings research was conducted in a distraction-free room.

Number discrimination (as prerequisite knowledge) at 24 months was assessed as measured with the manual search task while children sat on their mother's lap. Parents were instructed to remain neutral and not to elicit the child's attention during task administration. At 24 months children participated, furthermore, in a structured play observation with the mother.

The tests on number sense at 48 months took place individually in absence of any parents, in the same order for all participants. First, an intelligence test (the Wechsler Preschool and Primary Scale of Intelligence - Third edition (Hendriksen \& Hurks, 2009) was administered, followed by the assessment of a test battery on early mathematical competencies.

Both at 24 and 48 months the parents were asked to fill out a questionnaire containing general and more specific questions about their toddler's home experiences.

Parents signed an informed consent before participation with their child and the study was approved by the ethical commissions of the Faculty.

\section{Child distal factors: prerequisite math related knowledge at 24 months}

A manual search paradigm presenting as described by Feigenson and Carey (2005) was used to assess children's math related prerequisite knowledge or number sense at 24 months. Children sat on their parent's lap at an empty table in front of the experimenter. A wooden box $(25 \mathrm{~cm} \times 12.5 \mathrm{~cm} \times 31.5 \mathrm{~cm})$ had a slit at the front oriented to the toddlers and an opening at the backside of the box which was oriented to the experimenter. Parents were told that some balls would be hidden into this box to explore how children reacted and that no wrong reaction existed. Parents could only redirect their child's attention when (really) necessary, but were furthermore not allowed to help and were asked to further minimize communication. In this task, three kinds of trials existed. First, there was a box empty trial after which children were allowed to retrieve a hidden ball. Second, a more remaining trial followed, wherein the researcher hid three balls, but surreptitiously took away two, allowing the child to only retrieve one ball. Third, there was a second ("extended") box empty trial - always following the more remaining trial - in which the experimenter inserted again the balls that he took away through the backside of the box and offered the child to help, resulting in the child retrieving all (once) hidden balls. Each of the trial types were presented twice and the order of the trials was counterbalanced. Infants' cumulative searching time was coded manually afterwards using The Observer XT software for analysis of observational data. Two experimenters - who coded the observational data of the manual search task - achieved an averaged inter-rater reliability of 0.97 percentage of agreement. Subtracting searching time after box empty trials from searching time after more remaining trials resulted in difference scores. Reliability of the difference scores, as measured with Cronbach's $\alpha$, was 0.79 for this task. The reliable change index $(\mathrm{RCl})$ was computed following the procedure of Morley (2013) to find out whether the difference between the searching times at the different trial types was real or reliable. This method is generally used for defining a meaningful change (e.g., Jacobson \& Truax, 1999) and/or evaluating clinical data for which no control group is available against which the sample group can be compared (e.g., Fenton \& Morley, 2013).

\section{Parental non-numerical control variable: involvement}

General (non-numerical) involvement of parents was assessed as 'distal factor' and control variable with a parent questionnaire. Items on parental (i.e., maternal) involvement $(n=10)$ were retrieved from the scale 'Parental Involvement in Developmental Advance (PIDA)' from the StimQ-Toddler interview (Dreyer, Mendelsohn, \& Tamis-LeMonda, 1996) describing 
possible actions or activities with the child on initiative of the mother in the home environment on which parents could indicate "Yes" or "No" with one credit given for each positive answer (e.g., "Do you play make-believe games with your child in which you sit at the table or on the floor?" at 24 months or "Do you often have the opportunity to point to things in the street or around the house and name them for your child?" at 48 months). The StimQ has a high internal consistency as shown by a Cronbach's a ranging from 0.88 to 0.93 on each of the Stim $Q$ forms.

\section{Numerical opportunity factors}

A structured play situation at 24 and 48 months aimed to measure the frequency of spontaneous numerical behaviors of mother and child. Mother and child sat on a carpet fabricated of soft plastic and were instructed to build a house with a set of 'Duplo' blocks according to a model. The purpose was to give all the participants the opportunity to focus on these (inconsistent) numerical cues during the play. Both mother and child were blind for the true intention of the structured play observation. They were asked to play in a similar way as they would do at home. The structured play was recorded on video and all numerical actions of mothers and/or children were coded manually afterwards. All actions were given a score according to their frequency during the observation. The sum of all these frequency scores on numeracy interaction items resulted, finally, in the 'numeracy opportunity score'. At 24 months two experimenters achieved an averaged inter-rater reliability of 0.88 . At 48 moths two experimenters achieved an averaged inter-rater reliability of 0.84 percentage of agreement.

\section{Outcome: math achievement at 48 months}

At 48 months counting and early arithmetic skills were assessed with the TEDI-MATH (Grégoire et al., 2004). The value of the TEDI-MATH has been demonstrated in several studies (Desoete \& Grégoire, 2006; Desoete, Stock, Schepens, Baeyens, \& Roeyers, 2009; Stock, Desoete, \& Roeyers, 2007). Cronbach's Alpha for the different subtests vary between 0.70 and 0.97 (Grégoire et al., 2004). Counting items contained both procedural and conceptual counting knowledge. Procedural knowledge included accuracy in counting row and counting forward to an upper bound and/or from a lower bound. Conceptual knowledge implied the validity of counting procedures, based on the five basic counting principles formulated by Gelman and Gallistel (1978). Children had to judge the counting of linear and non-linear patterns of objects, and were asked questions about the counted amount of objects (e.g., "How many objects are there in total?"). Furthermore, they had to construct two numerical equivalent amounts of objects and use counting as a problem-solving strategy in a riddle. In addition early calculations skills were assessed using visually supported additions and subtractions. Children did to do the subtraction or addition and give the total. Reliability, as measured with Cronbach's $\alpha$, was 0.73 .

\section{Results}

Linear regression analyses were performed to explore the research questions. Graphical inspection of the data revealed that error terms were normally distributed. Since not only the quantity of opportunities might be important, not only linear but also quadratic relationships were explored. Only in case of a significant quadratic relationship this was mentioned additionally, next to the results of the linear relationship between certain variables. Moreover significant relationships between the opportunities were tested by taking into account the control variable (parental involvement). Each factor was only taken into account as a control measure when it correlated significantly with the relevant outcome (math achievement at 24 and 48th months). Table 2 provides the explorative correlations between all relevant measures included in the current study. 
Table 2. Correlations between distal, opportunity, propensity factors and later achievement

\begin{tabular}{|c|c|c|c|c|c|c|c|c|}
\hline & & \multicolumn{2}{|c|}{$\begin{array}{l}1 . \\
(0)\end{array}$} & \multicolumn{2}{|c|}{$\begin{array}{l}2 . \\
(0)\end{array}$} & $\begin{array}{l}3 . \\
(P)\end{array}$ & $\begin{array}{l}4 . \\
\text { (A) }\end{array}$ & $\begin{array}{l}5 . \\
\text { (A) }\end{array}$ \\
\hline & & $24 m$ & $48 m$ & $24 m$ & $48 m$ & $24 m$ & $48 m$ & $48 m$ \\
\hline $\begin{array}{l}\text { 1. Numerical } \\
\text { home } \\
\text { Opportunities } \\
\text { (O) }\end{array}$ & $\begin{array}{l}24 m \\
48 m\end{array}$ & $-.44^{* *}$ & - & & & & & \\
\hline $\begin{array}{l}\text { 2.Parental } \\
\text { Involvement (D) }\end{array}$ & $\begin{array}{l}24 m \\
48 m\end{array}$ & $\begin{array}{l}0.22 \\
0.03\end{array}$ & $\begin{array}{l}0.32 \\
.37^{\star *}\end{array}$ & $\overline{0} .17$ & - & & & \\
\hline $\begin{array}{l}\text { 3.Prerequisite } \\
\text { math } \\
\text { knowledge }(P)\end{array}$ & $24 m$ & $\begin{array}{l}0.02 \\
.1489\end{array}$ & -0.14 & -0.16 & -0.05 & - & & \\
\hline $\begin{array}{l}\text { 4.Procedural } \\
\text { Counting(A) }\end{array}$ & $48 m$ & $\begin{array}{l}0.15 \\
.343 \\
.434 \\
\end{array}$ & 0.29 & $0.39^{*}$ & 0.29 & -.03 & - & \\
\hline $\begin{array}{l}\text { 5. Conceptual } \\
\text { Counting }(A)\end{array}$ & $48 m$ & $\begin{array}{l}0.34^{*} \\
.343 \\
.434 \\
\end{array}$ & $\begin{array}{r}-.000 \\
.280\end{array}$ & -0.05 & 0.12 & -.03 & $\begin{array}{l}0.38^{* *} \\
.408\end{array}$ & - \\
\hline $\begin{array}{l}\text { 6.Calculation } \\
\text { (A) }\end{array}$ & $48 m$ & $\begin{array}{l}0.28 \\
.343 \\
.434\end{array}$ & $.40^{\star *}$ & 0.29 & $0.33^{*}$ & $\begin{array}{l}-.07 \\
.191\end{array}$ & $0.41^{\star *}$ & $0.57^{* * *}$ \\
\hline
\end{tabular}

Note. $\mathrm{m}=$ months, $\mathrm{O}=$ opportunity, $\mathrm{P}=$ propensity; $\mathrm{A}=$ achievement (outcome) ${ }^{*} p<.10,{ }^{* *} p<.05,{ }^{* \star *} p<.01$

Significant correlations between control factors and numerical outcome variables can be checked in this Table.

\section{Cross-sectional relationship between opportunities and prior-achievement at 24 months}

Linear regression analysis with (specific) home numeracy opportunities (numerical motherchild interaction) in toddlerhood demonstrated no significant linear relationship with the math related prerequisite knowledge measured with a manual search task $(T 1), F(1,27)=0.01, p=$ 0.932 .

\section{Cross-sectional relationship between opportunities and math achievement at 48 months}

Linear regression analysis with (specific) home numeracy opportunities in kindergarten revealed a significant positive linear relationship, $F(1,29)=5.56, p=0.025, \mathrm{R}^{2}=0.161$ with an effect size of $r=0.40$, for the home numeracy opportunities on the early arithmetic skills (as number sense) which remained marginally significant on top of the parental control variables, $F_{\text {change }}(1,28)=3.11, p=0.089, \mathrm{R}^{2}$ change $=0.09$.

Mediation analysis revealed, in addition, that the relationship between the parental involvement and later math achievement was (marginally significantly) mediated by the numerical opportunities in kindergarten, $\beta=0.321, p=0.089$.

\section{Prediction of opportunities at 24 months and achievement at 48 months}

Linear regression analysis with the specific (home) numeracy opportunities at 24th months revealed a trend of prediction for conceptual counting at 48 months, $F(1,27)=3.60, p=.068$. In 
addition, although not linear $F(1,27)=2.29, p=0.142$, a significant quadratic (positive) relationship could be found, $F(2,26)=3.68, p=0.039, \mathrm{R}^{2}=0.221$ between the opportunities at 24 months and the early calculation skills at 48 months with an effect size of $r=0.470$.

\section{Discussion}

A bulk of research exists on early literacy achievement through parent-child interactions as home numeracy opportunities from infancy on (e.g., Karrass \& Braungart-Rieker, 2005). The current study questioned whether home numeracy opportunities in children younger than kindergarten age could have a similar importance as predictors of later (concurrent or later) early math achievement.

\section{Home numeracy opportunities and achievement in kindergarten}

A significant linear relationship was found between more numerical opportunities (motherchild interaction) and concurrent early math achievement in kindergarten. This implies that how kindergartners performed on visually supported simple addition and subtraction exercises was related to the amount of numerical interactions between mother and child. As such, the parental numerical interaction might be perceived as a factor or opportunity that stimulates the child's development of numerical abilities in a positive way. However, it is also possible that parents who talk more about numbers or act more on numeracy, do so because their children are (initially more) interested in numbers or have better prerequisite knowledge. Prerequisite knowledge is considered within the opportunity propensity model as a propensity factor directly affecting later achievement. Children might, accordingly, provoke numerical interactions of their parents themselves. Therefore, it cannot be ruled out that mothers, who know this, are involved in numerical interactions. Children's academic performance or prerequisite knowledge may shape parental expectations (distal factors in the opportunitypropensity model), which in turn would predict children's subsequent achievement (Sy et al., 2013). Nevertheless, for the current data this means that either more numerical mother-child interaction resulted in better performance in arithmetic operations or children with more prerequisite knowledge elicited more numerical interactions. No causal relationship could be drawn because of the cross-sectional nature of the analysis.

Nonetheless, the value of those specific kinds of interactions could be demonstrated even when taking into account parental involvement as distal factor and plausible explaining factor. In line with Blevins-Knabe et al. (2007) it was reasonable to expect an effect of maternal involvement on numerical competencies, as this factor also related to literacy skills (e.g., Dodici et al., 2003). Likewise, a significant relationship was found between parental involvement and the early arithmetic skills of young children. Numerical mother-child opportunities in kindergarten not only had an additional value on top of maternal involvement, but also mediated the expected relationship between maternal involvement and the later numerical achievement. Therefore, it was suggested that the influence of those kinds of opportunities and interactions on children's later math achievement was not entirely due to an overall higher parental involvement.

\section{Home numeracy opportunities in toddlerhood and achievement in kindergarten}

The opportunity-propensity model especially uses longitudinal data to fine-tune predictions. Regarding the predictive value of numeracy environment (mother-child interaction in toddlerhood) for later math achievement, findings were in line with the results about the relationship between the parental numeracy opportunities and concurrent math achievement of children.

A positive relationship was found between parental opportunities and early math achievement. While the concurrent relationship between the constructs at kindergarten age (48 months) was linear, the relationship at toddler age (24 months) was quadratic in nature.

In kindergarten this implied that more numerical opportunities correlated with higher math achievement. In toddlerhood, however it seemed that more opportunities only predicted higher achievement in kindergarten to some extent. At higher rates later achievement declined again. This finding suggests that numerical stimulation through parent-child opportunities might be worthwhile for later math achievement, although its positive effect is not unlimited and might also depend on other factors such as aptitude, motivation and selfregulation. A child's readiness to move forward might not only depends on the opportunities in this case through numerical mother-child interaction, but also on the child's motivation and 
skills to engage in the activity.

\section{Home numeracy opportunities and early math achievement in toddlerhood}

The aim of this study was to investigate the relationship of these early numerical experiences in toddlerhood with early numeracy performance of children demonstrated by their number discrimination performance as prerequisite knowledge and performance on a manual search task at toddler age (24 months). No significant relationship was present in the current dataset. This suggests that numeracy stimulation in toddlerhood does not yet influence number sense, at least not the kind of numeracy measured with the search task. However, it might also be that the task was not sensitive enough to detect individual differences in number sense and was therefore not able to reveal relationship with opportunities in the environment. The kind of task itself, the low number of trials per child or the small sample size itself may account for this non-significant result.

That no concurrent relationship was found in toddlerhood is however not detrimental to the value of numerical parental opportunities as its predictive value was demonstrated by a prospective relationship with outcome in kindergarten. The current findings highlighted the long-term effects of numerical mother-child interaction rather than short-term effects, which in in this case are not even demonstrated. Accordingly, it can be concluded that the parental numeracy environment does not predict children's first acquired number sense skills such as reciting the counting sequence or learning the underlying principles of counting. The positive influence of numerical mother-child interaction seems to act on a more complex level later in development. It is however still conceivable that a concurrent relationship does exist between numeracy opportunities and more basic propensities home at younger age. This question could however not be answered based on the current data as only one aspect of numeracy was highlighted in toddlerhood. Future research should overcome this limitation by examining a broader range of numerical propensities and opportunities both in toddlerhood as in kindergarten, to elucidate this hypothesis.

\section{Specific numeracy environmental opportunities}

An important issue to this study related to the domain-specific nature of the opportunities on early numerical abilities of young children. The findings seemed to point in the direction of a numeracy specific relationship between mother-child interaction and early numeracy since overall no significant relationships were found between general involvement and the manual search task performance in toddlerhood or in kindergarten. Only once a significant relationship existed between maternal involvement in kindergarten and the concurrent performance on arithmetic operations as well as the observed numerical mother-child interaction in kindergarten. Nonetheless, controlling for the effect of this parental factor, the relationship between the frequency of numerical parent-child opportunities and number sense remained marginally significant. Therefore, it can be concluded that the influence of numerical interaction on children's early numeracy performance is not (only) due to an overall and general involvement of parents towards their children. In line with Hong, Yoo, You and Wu (2010) it could be expected that parental involvement with a domain-specific focus (i.e., numerical cues) may yield different results than a general approach of both factors. The current data may underpin this assumption since general parental involvement as distal factor could not fully explain the results found in this study.

\section{Implications}

To explore the relative importance of predictors of numeracy, an opportunity-propensity analysis was used to integrate home environment, prerequisite knowledge and parental involvement as opportunity, propensity and distal factors predicting early math achievement. The confirmative findings of the current study imply that an additional focus on numeracy (next to literacy) by agencies in support of parenting in preschoolers including infants and toddlers could be worthwhile.

At clinical level this research lays the foundation for a follow-up of those children who received less home environmental opportunities at the age of 2 years. If less parental input on numeracy is predictive of later mathematical problems, additional numerical stimulation of children at risk, could be worthwhile. Children at risk are those who perform less due to specific child or socio-cultural factors such as siblings of children with a mathematical disability who have a higher risk on having this disability too (e.g., Shalev et al. 2001) or children from families with a low income (e.g., Jordan, Kaplan, Locuniak, \& Ramineni, 2007). After all, 
positive parenting practices can protect children from, for example, the disadvantages of financial strain (Gershoff, Aber, Raver, \& Lennon, 2007; Yeung, Linver, \& Brooks-Gunn, 2002).

\section{Limitations and suggestions}

There are some limitations to this study. The first limiation is the sample size. Additional studies are needed to include more distal, opportunity and propensity factor as usually done in opportunity-propensity analyes on secundary data. In addition, this study dealt with families recruited from a subpopulation that already participated in the broader project of which this study was only a part. Therefore, the parents might have had an unusual high interest in engaging in educational activities with their children (Benigno \& Ellis, 2004). Another limitation is that only families with a middle or high family income were included. From previous studies it is known that middle-SES mothers engage their children in more complex number activities than low-SES mothers, leading to better developed skills (Starkey, Klein, \& Wakeley, 2004). It would therefore be interesting for future research to also take into account low-income families to accurately investigate the influence of SES on both numerical interaction and performance. Additional information could also be harvested by studying a broader range of numerical abilities both in toddlerhood and kindergarten.

\section{Conclusion}

Despite the mentioned limitations, the strength and unique contribution of the current study to research on early numeracy lies in the combination of opportunities and propensities and in predictive value of the opportunities (amount of numerical parental interaction) even in toddlerhood for numerical competencies of children in kindergarten. Moreover, this study informs about the different kind of relationship of numerical mother-child interaction in toddlerhood compared to later math achievement in kindergarten. As this relationship was confirmed to be linear in kindergarten, one could - so to speak - simply promote engagement in these kinds of interactions. As, however, the positive effect on later achievement of the same interactions in toddlerhood seems not unlimited, fostering numerical development within relative boundaries is indicated. Emphasis is therefore mainly on empowerment of opportunities to foster numerical development within children's zone of proximal development (even) from toddlerhood on. Future research needs to clarify long-term effects of these specific home environmental opportunities experiences on typical and atypical development of numeracy to explore further clinical relevance. 


\section{References}

Anders, Y., Rossbach, H.G., Weinert, S., Ebert, S., Kuger, S., Lehrl, S., \& von Maurice, J. (2012). Home and preschool learning environments and their relations to the development of early numeracy skills. Early Chilhood Research Quarterly, 27(2), 231-244. http://dx.doi.org/10.1016/j.ecresq.2011.08.003

Benigno, J. P., \& Ellis, S. (2004). Two is greater than three: Effects of older siblings on parental support of preschoolers' counting in middle-income families. Early Childhood Research Quarterly, 19(1), 4-20. http://dx.doi.org/10.1016/j.ecresq.2004.01.006

Benavides-Varela, S., Butterworth, B., Burgio, F., Arcara, G., Luc angeli, D., \& Semenza, C. (2016). Numerical activities and information learned at home link to the exact numercay skills in 5-6 years-old Children. Frontieres in Psychology, 7, 94. http://dx.doi.org/10.3389/fpsyg.2016.00094

Blevins-Knabe, B., \& Musun-Miller, L. (1996). Number use at home by children and their parents and its relationship to early mathematical performance. Early Development \& Parenting, 5(1), 35-45. http://dx.doi.org/10.1002/(sici)1099-0917(199603)5:1<35::aid-edp113>3.0.co;2-0

Blevins-Knabe, B., Whiteside-Mansell, L., \& Selig, J. (2007). Parenting and mathematical development. Academic Exchange Quarterly, 11(2), 76-80.

Clements, D.H., \& Sarama, J. (2014). The importance of early years. In R.E. Slavin (Ed.), Science, technology \& mathematics (STEM) (pp. 5-9). Thousand Oaks, CA: Corwin.

Desoete, A., \& Baten, E. (2017). Indicators for a specific learning disorder in mathematics or dyscalculia in toddlers and in kindergarten children. Belgian Journal of Paediatrics, 19 (2), 117-120.

Desoete, A., \& Grégoire, J. (2006). Numerical competence in young children and in children with mathematics learning disabilities. Learning and Individual Differences, 16(4), 351-367. http://dx.doi.org/ 10.1016/j.lindif.2006.12.006

Desoete, A., Stock, P., Schepens, A., Baeyens, D., \& Roeyers, H. (2009). Classification, seriation, and counting in grades 1,2 , and 3 as two-year longitudinal predictors for low achieving in numerical facility and arithmetical achievement? Journal of Psychoeducational Assessment, 27(3), 252-264. http://dx.doi.org/10.1177/0734282908330588

Dieterich, S. E., Assel, M. A., Swank, P., Smith, K. E., \& Landry, S. H. (2006). The impact of early maternal verbal scaffolding and child language abilities on later decoding and reading comprehension skills. Journal of School Psychology, 43(6), 481-494. http://dx.doi.org/10.1016/j.jsp.2005.10.003

Dodici, B. J., Draper, D. C., \& Peterson, C. A. (2003). Early parent-child interactions and early literacy development. Topics in Early Childhood Special Education, 23(3), 124-136. http://dx.doi.org/ $10.1177 / 02711214030230030301$

Dreyer, B.P., Medelsohn, A.L., \& Tamis-LeMonda, C.S. (1996). Assessing the child's cognitive home environment through parental report: Reliability and validity. Early Development \& Parenting, 5(4), 271287. http://dx.doi.org/10.1002/(SICI)1099-0917(199612)5:4<271::AID-EDP138>3.0.CO;2-D

Feigenson, L., \& Carey, S. (2005). On the limits of infants' quantification of small object. Cognition, 97(3), 295-313, http://dx.doi.org/10.1016/j.cognition.2004.09.010.

Fenton, G., \& Morley, S. (2013). A tale of two RCTs: Using randomized controlled Trials to Benchmark routine clinical (psychological) treatments for chronic pain. Pain, 154(10), 2108-2119. http://dx.doi.org/10.1016/j.pain.2013.06.033

Gelman, R., \& Gallistel, C. R. (1978). The child's understanding of number. Cambridge, MA: Harvard University Press.

Gershoff, E. T., Aber, J. L., Raver, C. C., \& Lennon, M. C. (2007). Income is not enough: Incorporating material hardship into models of income associations with parenting and child development. Child Development, 78(1), 70-95. http://dx.doi.org/10.1111/j.1467-8624.2007.00986.x

Grégoire, J. (2005). Développement logique et compétences arithmétiques. Le modèle piagétien est-il toujours actuel ? [Development of logical competences in arithmetics. Is the Piagetian model still up to date?]. In M. Crahay, L. Verschaffel, E. De Corte \& J. Grégoire (eds.), Enseignement et apprentissage des mathématiques (pp. 57-77). Bruxelles: De Boeck.

Grégoire, J., Noël, M., \& Van Nieuwenhoven, C. (2004). TEDI-MATH. Antwerpen: Harcourt.

Hong, S., Yoo, S.K., You, S., \& Wu, C.C. (2010) The reciprocal relationship between parental involvement and mathematics achievement: autoregressive cross-lagged modeling. The Journal of Experimental Education, 78(4), 419-439. http://dx.doi.org/10.1080/00220970903292926

Hood, M., Conlon, E., \& Andrews, G. (2008). Preschool home literacy practices and children's literacy 
development: A longitudinal analysis. Journal of Educational Psychology, 100(2), 252-271. http://dx.doi.org/10.1037/0022-0663.100.2.252

Huntsinger, C.S., Jose, P.E., Larson,S.L., Balsink Krieg, D., \& Shaligram, C. (2000). Mathematics, vocabulary, and reading development in Chinese American and European American Children over the primary school years. Journal of Educational Psychology, 92(4), 745-760, http://dx.doi.org/ 10.1037//0022-0663.92.4.745

Jacobson, N.S, \& Truax P. (1991). Clinical significance: A statistical approach to defining meaningful change in psychotherapy research. Journal of Consulting and Clinical Psychology, 59(1), 12-19. http://dx.doi.org/10.1037/0022-006X.59.1.12

Jordan, N. C., Kaplan, D., Locuniak, M. N., \& Ramineni, C. (2007). Predicting first-grade math achievement from developmental number sense trajectories. Learning Disabilities Research \& Practice (Blackwell Publishing Limited), 22(1), 36-46. http://dx.doi.org/10.1111/j.1540-5826.2007.00229.x

Karrass, J., \& Braungart-Rieker, J. M. (2005). Effects of shared parent infant book reading on early language acquisition. Journal of Applied Developmental Psychology, 26(2), 133-148. http://dx.doi.org /10.1016/j.appdev.2004.12.003

Kleemans, T., Peeters, M., Segers, E., \& Verhoeven, L. (2012). Child and home predictors of early numeracy skills in kindergarten. Early Childhood Research Quarterly, 27(3), 471 - 477. http://dx.doi.org/10.1016/j.ecresq.2011.12.004

Landry, S. H., Smith, K. E., \& Swank, P. R. (2006). Responsive parenting: Establishing early foundations for social, communication, and independent problem-solving skills. Developmental Psychology, 42(4), 627-642. http://dx.doi.org/10.1037/0012-1649.42.4.627

Le Fevre, J. A., Skwarchuk, S. L., Smith-Chant, B. L., Fast, L., Kamawar, D., \& Bisanz, J. (2009). Home Numeracy Experiences and Children's Math Performance in the Early School Years. Canadian Journal of Behavioural Science, 41(2), 55-66. http://dx.doi.org/10.1037/a0014532

Levine, S. C., Suriyakham, L. W., Rowe, M. L., Huttenlocher, J., \& Gunderson, E. A. (2011). What counts in the development of young children's number knowledge? Developmental Psychology, 47(5), 302-302. http://dx.doi.org/10.1037/a0022101

Melhuish, E.C., \& Phan, M.B. (2008). Effects of the home learning environment and preschool center experience upon literacy and numeracy development in early primary school. Journal of Social Issues, 64(1), 95-114.

Morley, S. (2013). A rough guide to evaluating your Pain Management Programme: The analysis of individual patient data and benchmarking. Unpublished manuscript, University of Leeds.

Niklas, F., Cohrssen, C., \& Tayler, C. (2016). Improving preschooler's numerical abilities by enhancing the home numeracy environment. Early Educaton and Development, 27(3), 372-383. http://dx.doi.org/10. 1080/10409289.2015.1076676

Pancsofar, N., Vernon-Feagans, L., \& Family Life Project, I. (2010). Fathers' early contributions to children's language development in families from low-income rural communities. Early Childhood Research Quarterly, 25(4), 450-463. http://dx.doi.org/10.1016/j.ecresq.2010.02.001

Roberts, J. E., Jurgens, J., \& Burchinal, M. (2005). The role of home literacy practices in preschool children's language and emergent literacy skills. Journal of Speech Language and Hearing Research, 48, 345-359. http://dx.doi.org/10.1044/1092-4388(2005/024)

Segers, E., Kleemans, T., \& Verhoeven, L. (2015). Role of parent literacy and numeracy expectations and activities in predicting early numeracy skills. Mathematical Thinking and Learning, 17(2-3), 219-236. http://dx.doi.org/10.1080/10986065.2015.1016819

Senechal, M., \& LeFevre, J. A. (2002). Parental involvement in the development of children's reading skill: A five-year longitudinal study. Child Development, 73(2), 445-460. http://dx.doi.org/10.1111/14678624.00417

Shalev, R. S., Manor, O., Kerem, B., Ayali, M., Badichi, N., Friedlander, Y., \& Gross-Tsur, V. (2001). Developmental dyscalculia is a familial learning disability. Journal of Learning Disabilities, 34(1), 59-65. http://dx.doi.org/10.1177/002221940103400105

Skwarchuk, S.L., Sowinksi, C., LeFevre, J.A. (2014). Formal and informal home learning activities in relation to children's early numeracy and literacy skills: the development of a home numercay model. Journal of Experimental Child Psychology, 121, 63-84. http://dx.doi.org/10.1016/j.jecp.2013.11.006.

Starkey, P., Klein, A., \& Wakeley, A. (2004). Enhancing young children's mathematical knowledge through a pre-kindergarten mathematics intervention. Early Childhood Research Quarterly, 19(1), 99-120. http://dx.doi.org/10.1016/j.ecresq.2004.01.002 
Stock, P., Desoete, A., \& Roeyers, H. (2007). Early markers for arithmetic difficulties. Educational and Child Psychology, 24, 28-39.

Sy, S.R., Gottfried, A.W., \& Gottfried, A.E. (2013). A transactional model of parental involvement and children's achievement from early childhood through adolescence. Parenting sciance and practice, 13(2), 133-152. http://dx.doi.org/10.1080/15295192.2012.709155

Yeung, W. J., Linver, M. R., \& Brooks-Gunn, J. (2002). How money matters for young children's development: Parental investment and family processes. Child Development, 73(6), 1861-1879. http://dx.doi.org/10.1111/1467-8624.t01-1-00511. 